\title{
Hybrid cork-polymer composites containing sisal fibre: Morphology, effect of the fibre treatment on the mechanical properties and tensile failure prediction
}

\author{
Emanuel M. Fernandes*, João F. Mano, Rui L. Reis \\ 3B's Research Group - Biomaterials, Biodegradables and Biomimetics, University of Minho, Headquarters of the European Institute of Excellence on Tissue Engineering \\ and Regenerative Medicine, AvePark, 4806-909 Taipas, Guimarães, Portugal \\ ICVS/3B's - PT Government Associate Laboratory, Braga/Guimarães, Portugal
}

\section{A R T I C L E I N F O}

Article history:

Available online 23 May 2013

\section{Keywords:}

Polymer-matrix composites (PMCs)

Hybrid composites

Extrusion

Mechanical behaviour

Fibre reinforced plastic

Cork

\begin{abstract}
A B S T R A C T
In this study, we investigated the use of short sisal fibre with and without polyethylene-graft-maleic anhydride (PE-g-MA) as a strategy to reinforce cork-polymer composite (CPC) materials. The use of alkali treatment of sisal to improve fibre-matrix adhesion was evaluated. High density polyethylene (HDPE) was used as matrix and the composites were produced in a two-step process using twin-screw extruder followed by compression moulding. FTIR, TGA and XRD were used to confirm the sisal fibre modification. Additionally, morphology, density, diameter and tensile properties of the fibres were evaluated before processing. The hybrid composites containing cork powder ( $40 \mathrm{wt} . \%$ ) and randomly distributed sisal fibres were evaluated in terms of morphology and mechanical properties. The use of a $10 \mathrm{wt} . \%$ sisal fibre in the presence of a 2 wt.\% coupling agent based on maleic anhydride, has shown to improve the tensile and flexural properties of the composites. The higher mechanical properties were achieved by using alkali treated sisal fibres and PE-g-MA. In the presence of the coupling agent the composite morphology revealed good interfacial adhesion between the natural components and the polypropylene matrix, being in accordance with the mechanical results. Weibull cumulative distribution was successfully used to accurately predict the tensile strength failure of the hybrid CPC materials.
\end{abstract}

(c) 2013 Elsevier Ltd. All rights reserved.

\section{Introduction}

In the last years, natural fibres reinforced composites have received high attention due to their low density, excellent thermal properties, low cost, biodegradability, availability, non-toxicity

Abbreviations: $\alpha$, scale parameter or denotes significance level; $\beta$, shape parameter; $\mu$, mean; $\sigma$, variance; $A_{\text {cryst }}$, crystalline area; $A_{\text {total, }}$, total area; ATR, attenuated total reflectance; $\mathrm{CNC}$, computer numerical control; $\mathrm{CO}_{2}$, carbon dioxide; \% $\mathrm{Cr}$, crystallinity percentage; $\mathrm{CPCs}$, cork-polymer composites; $\mathrm{CV}$, critical value $\left(\alpha^{\prime}\right) ; D_{n}$, maximum deviation; $D_{n c}$, critical value from K-S test table; $F_{0}$ Weibull cumulative distribution function; $F n$, cumulative observed values; $F(x)$, probability of failure; FTIR, Fourier transform infrared spectroscopy; HDPE, high density polyethylene; $L$, span; $L / D$, extruder length-to-diameter ratio; $K-S$, Kolmogorov-Smirnov; MA, maleic anhydride; $n$, denotes sample size or number of measurements; $\mathrm{NaOH}$, sodium hydroxide; $p$, denotes probability; PE, polyethylene; PE-g-MA, polyethylene-graft-maleic anhydride; PP, polypropylene; $x$, applied stress (strength); SEM, scanning electron microscope; WAXRD, wide-angle X-ray diffraction.

* Corresponding author at: 3B's Research Group - Biomaterials, Biodegradables and Biomimetics, University of Minho, Headquarters of the European Institute of Excellence on Tissue Engineering and Regenerative Medicine, AvePark, 4806-909 Taipas, Guimarães, Portugal. Tel.: +351 253 510900; fax: +351 253510909

E-mail address: efernandes@dep.uminho.pt (E.M. Fernandes). and absorbing $\mathrm{CO}_{2}$ during their growth [1-4]. Although, certain drawbacks, like incompatibility with the hydrophobic polymer matrix, the tendency to form aggregates during processing and the low resistance to moisture, reduce the potential of using natural fibres as reinforcement in polymers $[2,3,5]$. The incompatibility may cause problems in the composite processing and in the materials properties. The highly polar character of natural fibres have inherently low compatibility with nonpolar polymer matrices, especially hydrocarbon matrices such as polypropylene (PP) and polyethylene (PE) [5]. As a result, the polymer matrix is unable to transfer the stress to the filler through the interface when submitted to mechanical load, being the reinforcement efficiency reduced. Moreover moisture makes the use of natural fibre reinforced composites less attractive. Applying pre-treatments to the natural fibres can clean and chemically modify their surface, reduce the moisture absorption and increase surface roughness. These methods are able to ameliorate the fibre-matrix adhesion with a positive effect on the mechanical properties [4,6-9]. A classic method of cellulose fibre modification is mercerization, which is an alkali treatment where the natural and artificial impurities are removed, leading to fibrillation of the fibre bundle to smaller 
fibres [6,10,11], meaning lower fibre diameter and increasing the aspect ratio [10]. The proper conditions of mercerization ensure the improvement of the tensile properties $[3,11,12]$. Cork is the bark of the oak (Quercus suber L.) which is periodically harvested each 9-12 years [13]. This lignocellulosic material holds environmental benefits to be applied on a new generation of composite materials [14-16]. Just a few studies were performed to improve the cork-matrix performance of cork based composites using different strategies, including: (i) chemical modification of cork [15], (ii) the use of coupling agents [15,17] to promote cork-matrix bonding and (iii) the use of different natural or synthetic fibres to reinforce cork-polymer matrices [18-20]. The incorporation of different types of fibres into a single matrix has led to the development of hybrid composites. Hybrid composite materials that contain two or more types of fibre combine the advantages of one type of fibres with the lacking of properties in the other. As a consequence, a balance in cost and performance could be achieved through proper material design [21]. The properties of a hybrid composite depend on parameters such as fibre content, length and orientation of the fibres, fibre to matrix bonding and arrangement of the different fibres. The strength of the hybrid composite is also dependent on the failure strain of individual fibres. Maximum mechanical performance results are obtained when the fibres are highly strain compatible [22]. Sisal fibre is a cellulosic fibre obtained from leaves of an annually harvasted plant, called Agave sisalina and is one of the strongest of all plant fibres [8,23].

The aim of this work was to develop strategies to reinforce cork based composites with natural fibres, with and without chemical treatment, in the presence of low amounts of the coupling agent to ameliorate the mechanical properties. The production of hybrid composites was tested to obtain a composite with enhanced performance that could be used in complex geometries without failure, where cork cannot compete alone. Additionally one and two step extrusion processes were tested to evaluate the correct form to obtain the hybrid cork-polymer pellets reinforced with sisal fibres, to be applied in the compression moulding process in order to produce specimens of reinforced cork composites. The properties of the composites depend on the individual components and fibre-matrix interfacial compatibility. The Weibull distribution provides a reliable possibility to predict the tensile strength of a needed composite material, and this should be taken into account by the designer $[24,25]$. Therefore, in this work we also consider the Weibull distribution to be a viable tool to predict the tensile strength failure of the novel hybrid composites under analysis.

\section{Materials and methods}

\subsection{Materials}

Cork powder, with an average particle size $<500 \mu \mathrm{m}$ a specific weight of $157 \pm 2 \mathrm{~kg} \mathrm{~m}^{-3}$ and a humidity of $\sim 5.4 \%$ was supplied by Amorim Revestimentos S.A. (S. Paio Oleiros, Portugal). The sisal fibre from Madagascar, presents a diameter of $183 \pm 35 \mu \mathrm{m}$ and moisture of $\sim 11.3 \%$. The chemical composition of the used biofibres is present in Table 1 [7,13,26,27]. The matrix was a high density polyethylene, HDPE (HMA - 025) from ExxonMobil (Germany), with a MFI of $8.2 \mathrm{~g} \times 10 \mathrm{~min}^{-1}\left(190{ }^{\circ} \mathrm{C}, 2.16 \mathrm{~kg}\right)$, and a melting point of $136.6^{\circ} \mathrm{C}$. The coupling agent, a HDPE grafted with maleic anhydride (PE-g-MA), containing 0.5-1.0 wt.\% of maleic anhydride (Exxelor PE 1040) with MFI of $1.4 \mathrm{~g} \times 10 \mathrm{~min}^{-1}\left(190{ }^{\circ} \mathrm{C}, 2.16 \mathrm{~kg}\right)$, and a melting point of $131.3^{\circ} \mathrm{C}$, produced by ExxonMobil (Germany). The polymer and the coupling agent were supplied by Pallmann Maschinenfabrik GmbH \& Co. (Germany) after use a pulverizing system for plastics with particle size of $250 \mu \mathrm{m}$ to $1.2 \mathrm{~mm}$.

\subsection{Sisal fibre surface modification - alkali treatment}

The preparation of alkali treated sisal (Sisal_NaOH) was as follows [28]: the sisal fibres were immersed in sodium hydroxide $(\mathrm{NaOH})$ solution $(5 \% \mathrm{w} / \mathrm{v})$ for $2 \mathrm{~h}$ at room temperature. After that the fibres were washed with distilled water containing a few drops of acetic acid. Final washings were carried out with distilled water until neutrality $(\mathrm{pH}=7$ ), to remove the excess of $\mathrm{NaOH}$ present on the fibres, until this water no longer indicated any alkalinity reaction. Then, the fibres were air-dried at room temperature, followed by drying in a vacuum oven at $70^{\circ} \mathrm{C}$ and after stabilise was stored in polyethylene bags.

\subsection{Composite production}

Before compounding all raw materials were pre-dried at $80^{\circ} \mathrm{C}$ during $16 \mathrm{~h}$ to stabilise the cork and the sisal fibres in terms of moisture content. After that the sisal fibres were cut in dimensions $<20 \mathrm{~mm}$. The prepared compositions and processing conditions are summarized in Table 2. The compounding was performed in a counter-rotating twin-screw extrusion machine (Carvex, Portugal) which had a screw diameter of $52 \mathrm{~mm}$ and an $L / D$ ratio of 18 . The barrel temperature was in the range $130-160^{\circ} \mathrm{C}$, and the screw speed was fixed at $30 \mathrm{rpm}$. The cork powder and the grinding HDPE were pre-mixed and manually in small portions and feed in the hopper system with the sisal fibres. No extrusion head was used in order to minimize the residence time and shear heat dissipation. The extruded material was cooled in air, granulated in a cutting mill to produce hybrid composite pellets with dimensions $\leqslant 6 \mathrm{~mm}$. In a further step, compression moulding of the obtained pellets using a hydraulic press (Moore, UK) was applied to produce boards with $3 \mathrm{~mm}$ and $6 \mathrm{~mm}$ of thickness for tensile and flexural tests respectively. The mould conditions included temperature of $150{ }^{\circ} \mathrm{C}$ during $8 \mathrm{~min}$ and a pressure of $1.42 \mathrm{MPa}$ was applied during the last $2 \mathrm{~min}$. In the case of boards with thickness of $6 \mathrm{~mm}$ the temperature was increased to $160^{\circ} \mathrm{C}$. The cooling with water occurs in the mould under pressure [19]. Tensile and flexural specimens were obtained from these boards (see Fig. 1), using a computer numerical control CNC machine (Roland 3D Plotter MDX-20, UK).

\subsection{Fibre characterization}

\subsubsection{Chemical characterization}

To confirm the chemical treatment, the fibres were analysed using Fourier transform infrared (FTIR) spectroscopy. All the spectra were acquired using a Shimadzu IR-Prestige 21. The attenuated total reflectance (ATR) methodology (PIKE Technologies) was used and the spectra were acquired between $4400 \mathrm{~cm}^{-1}$ and $800 \mathrm{~cm}^{-1}$ using a resolution of $4 \mathrm{~cm}^{-1}$.

Table 1

Chemical constituents of selected composite reinforcements (wt.\%).

\begin{tabular}{|c|c|c|c|c|c|c|c|}
\hline Chemical composition & Cellulose & Hemicellulose & Lignin & Suberin & Extractives & Ash & Literature reference \\
\hline Cork & $12-13$ & 12 & 21 & $42-45$ & $13-19$ & 1.2 & {$[13,27]$} \\
\hline Sisal & $67-74$ & $10-14$ & $8-11$ & - & $2-6$ & 1.0 & {$[7,26]$} \\
\hline
\end{tabular}


Table 2

Designation and processing conditions of the hybrid composite formulations based on polyethylene-cork (60-40) wt.\%.

\begin{tabular}{|c|c|c|c|c|c|c|}
\hline \multirow[t]{2}{*}{ Code } & \multirow[t]{2}{*}{ HDPE (wt.\%) } & \multirow[t]{2}{*}{ Cork (wt.\%) } & \multirow[t]{2}{*}{ Sisal fibre (wt.\%) } & \multirow[t]{2}{*}{ Coupling agent (wt.\%) } & \multicolumn{2}{|l|}{ Extrusion conditions } \\
\hline & & & & & Temperature profile $\left({ }^{\circ} \mathrm{C}\right)$ & Motor (rpm) \\
\hline CPC 1 & 60.0 & 40.0 & - & - & $130 ; 145 ; 150$ & 30 \\
\hline CPC 2 & 58.8 & 39.2 & - & 2 & $130 ; 145 ; 150$ & 30 \\
\hline CPC 3 & 54.0 & 36.0 & 10 & - & $135 ; 150 ; 155$ & 30 \\
\hline${ }^{\mathrm{a}} \mathrm{CPC} 4$ & 54.0 & 36.0 & 10 & - & $135 ; 150 ; 155$ & 30 \\
\hline CPC 5 & 52.8 & 35.2 & 10 & 2 & $135 ; 150 ; 155$ & 30 \\
\hline CPC 6 & 52.8 & 35.2 & $10^{\mathrm{b}}$ & 2 & $135 ; 150 ; 155$ & 30 \\
\hline
\end{tabular}

a Pellets from CPC1 with 10 wt.\% of sisal fibre (two extrusion steps).

b Sisal fibre modified with $\mathrm{NaOH}$.

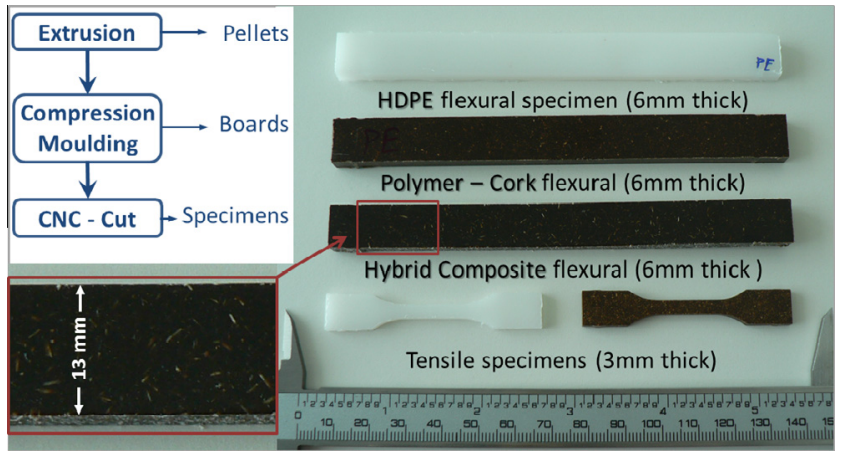

Fig. 1. Scheme of the process to obtain the composites and geometry of the specimens used in the tensile and flexural tests.

\subsubsection{Crystallinity}

To detect the crystalline structure of cellulose in sisal, wide-angle X-ray diffraction (WAXRD) diffractograms were recorded using the Bruker-AXS D8 Discover diffractometer in $\theta-2 \theta$ geometry using $\mathrm{Cu} \mathrm{K} \alpha 1,2$ lines collimated with a Gobël mirror, a divergent slit of $0.6 \mathrm{~mm}$, a detector slit of $1 \mathrm{~mm}$ and $0.6 \mathrm{~mm}$ and a Ni filter. The data was collected from $6-50^{\circ}$ with a step size of $0.04^{\circ}$ and an acquisition time of $1^{\circ}$ sec per step. The percentage of crystallinity $(\% \mathrm{Cr})$, performed using a fitting program, was calculated based on:

$\% \mathrm{Cr}=\left(A_{\text {cryst }} / A_{\text {total }}\right) \times 100$

where $A_{\text {cryst }}$ is the area below the diffraction peak of the (002) plane, peak at $2 \theta=22.5^{\circ}$, and from the (101) and (101) plane, peak at $\left(13-18^{\circ}\right)$, and $A_{\text {total }}$ is the area below the whole region in the XRD spectra representing the amorphous material in the cellulosic fibres.

\subsubsection{Fibre diameter and density}

The diameter measurements of sisal fibres with and without chemical treatment were made in five spaced locations along the gauge length of each specimen using an optical microscope Olympus BH-2 (Tokyo, Japan) equipped with an Olympus DP11, (Japan) digital camera. A histogram for each type of sisal fibre was performed and a normal distribution to characterize and compare the properties of the fibre with and without chemical treatment. The density of the sisal fibres was determined according to the standard ASTM D 792, using an analytical balance equipped with a stationary support for the immersion vessel. Five fibres were weighted per condition.

\subsubsection{Thermal degradation}

Thermogravimetric analyses (TGA) were performed to understand the degradation characteristics of the sisal fibres and confirm the chemical modification. The thermal stability was determined using a TGA Q500 series thermogravimetric analyser (TA Instruments, USA). Experiments were performed in platinum pans, at a heating rate of $10^{\circ} \mathrm{C} \mathrm{min}^{-1}$ from $50^{\circ} \mathrm{C}$ to $600{ }^{\circ} \mathrm{C}$ under nitrogen atmosphere. All tests were repeated once.

\subsubsection{Mechanical properties of sisal fibres}

Single fibre tensile tests were measured with a Instron 4505 Universal Machine (USA) using a $1 \mathrm{kN}$ load cell, a crosshead speed of $1 \mathrm{~mm} \mathrm{~min} \mathrm{~m}^{-1}$, and a fibre gauge length of $30 \mathrm{~mm}$. Prior to testing, fibres were mounted on sturdy paper frames using a high-strength hot melt glue and placed in a desiccators for a minimum period of $48 \mathrm{~h}$. The tensile properties of the single sisal fibres were determined according to the standard ASTM C 1557.

\subsection{Morphology of the fibres and the composites}

The morphological characterization of the natural fibres and the developed reinforced cork polymer composites fracture surface were examined using a NanoSEM 200 FEI (The Netherlands) scanning electron microscope (SEM). Before being analysed all the samples were coated by ion sputtering with an Au/Pd alloy (80$20 \mathrm{wt} . \%$ ) in a high resolution sputter coater of Cressington 208HR (Watford, UK).

\subsection{Mechanical properties of composites}

\subsubsection{Tensile tests}

The tensile properties of the developed cork based composites reinforced with sisal fibres were determined in the same machine according the standard ISO 527-2. The tensile bars had a neck cross-section area of $3 \times 4 \mathrm{~mm}^{2}$ and a neck length of $20 \mathrm{~mm}$. The tensile force was taken as the maximum force in the force deformation curve. Tensile modulus was estimated from the initial slope of the stress-strain curve (between $0.05 \%$ and $1 \%$ strain) using the linear regression method. Samples were conditioned at room temperature for at least $48 \mathrm{~h}$ before testing. A crosshead speed of $5 \mathrm{~mm} \mathrm{~min}^{-1}$ was used up to a strain at break. The average and standard deviations were determined using eight specimens per condition.

\subsubsection{Flexural tests}

Three point static flexural tests were carried out in accordance with standard ISO 178. The dimensions of the specimens used were $132 \mathrm{~mm}$ length, $13 \mathrm{~mm}$ width and $6 \mathrm{~mm}$ depth. The load was placed midway between the supports with a span (L) of $80 \mathrm{~mm}$. The crosshead speed was $2.56 \mathrm{~mm} / \mathrm{min}$. The tested specimens were performed in an Instron 4505 Universal Machine (USA) equipped with a $1 \mathrm{kN}$ cell load. For each condition, the specimens were loaded until the core break. The average and standard deviations were determined using 7 specimens.

\subsection{Statistical analysis}

The values obtained by tensile and flexural tests were analysed by the normality of the distribution of the mechanical results was 
evaluated using Shapiro-WilK test to evaluate their normal distribution at $p<0.05$. The means were compared using a Two-Sample $t$-Test or the non-parametric Kolmogorov-Smirnov (K-S) test and differences were considered significantly different at $p<0.05(*)$. Additionally and in order to predict the failure probability of the developed hybrid cork composites the values obtained from the tensile tests were statistically analysed by using the two-parameter Weibull model, where the cumulative distribution function is given by [29]:

$F(x)=1-\exp ^{-\left[\frac{x}{\alpha}\right]^{\beta}}, \quad$ for $x>0$

where $F(x)$ is the probability of failure of a composite material subjected to a stress level $x$. In Eq. (2), $\alpha$ and $\beta$ are two constants to be determined, known as the "scale parameter" or "characteristic strength" and the "shaper parameter", respectively. Finally the Kolmogorov-Smirnov test was employed to evaluate the goodness-offit to the data points.

\section{Results and discussion}

\subsection{Sisal fibre properties}

\subsubsection{Chemical characterization}

Natural fibres are chemically treated to remove lignin, pectin and waxy substances covering the external surface of the fibre cell wall [30]. The chemical composition change at the sisal fibre surface structure by the chemical treatment was characterized using ATR-FTIR spectroscopy. Fig. 2 shows the spectra region between 800 and $2000 \mathrm{~cm}^{-1}$ relative to unmodified fibre (Sisal), alkali treatment (Sisal_NaOH) which revealed that some changes did occur. In agreement with other previous works, the significant weight loss of sisal fibre after alkali treatment (see Table 3) can be attributed to the partial dissolution of hemicellulose [31], lignin and pectin [11]. The FTIR spectra confirm the disappearance of the carbonyl band (between 1660 and $1760 \mathrm{~cm}^{-1}$ ), when the fibre was treated with $\mathrm{NaOH}$. It was also reported before that alkali treatment reduces hydrogen bonding due to removal of the hydroxyl groups by reacting with sodium hydroxide [30]. The slightly diminished intensity of around $1610 \mathrm{~cm}^{-1}$ for the treated fibres could be attributed to the removal of some aromatic lignin-like impurities [31].

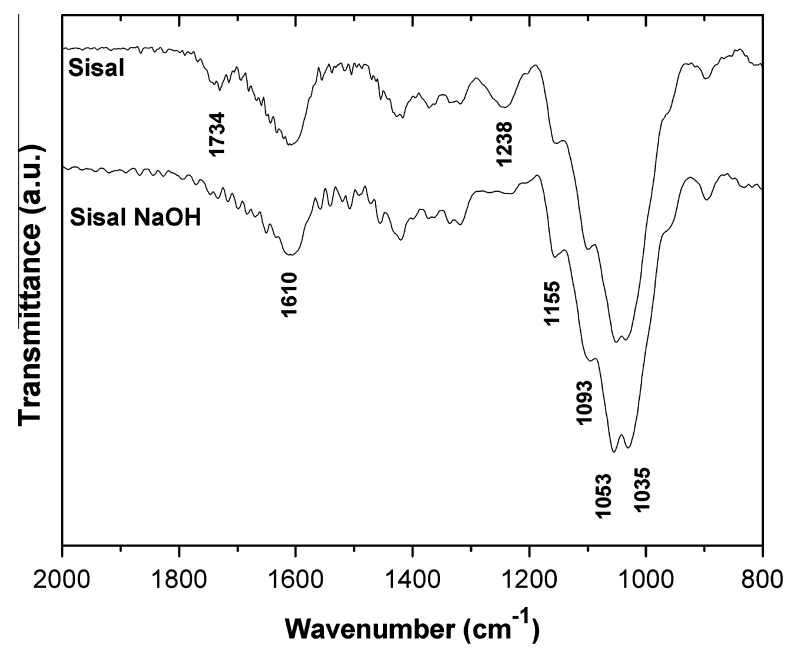

Fig. 2. ATR-FTIR spectra of unmodified sisal fibre and sisal with alkali treatment (Sisal $\mathrm{NaOH}$ ).

\subsubsection{Crystallinity}

The result of X-ray diffraction present in Fig. 3 reflects the influence of the surface treatment on the sisal fibres between the amorphous and crystalline regions. The spectra were almost similar; however, alkali-treated fibre peaks were more intense than untreated sisal peaks, which mean that the chemical treatment was able to remove part of the amorphous material covering the fibre, thus exposing the cellulose. Table 3 shows that a small increase on the cellulose crystallinity $(\% \mathrm{Cr}$ ) occurred when the sisal fibre was submitted to chemical treatment. The untreated sisal fibre has a $\% \mathrm{Cr}$ of $24.1 \%$ that increases to $29.6 \%$ after chemical modification with $\mathrm{NaOH}$. When the sisal fibre receives the alkali solution chemical treatment, the crystalline fraction of cellulose increased due to the partial elimination of lignin during alkaline treatment, losing part of its amorphous component [11]. This result is in accordance with the FTIR analysis. In the literature it is also indicated that thermal treatments on sisal fibres does not change significantly the chemical composition for temperatures below $200^{\circ} \mathrm{C}$ and increases the degree of crystallinity [32], therefore it is also expected the occurrence of this phenomenon during the melt based processes of extrusion and compression moulding involving the use of sisal fibres.

\subsubsection{Diameter, density and morphology}

The fibre diameter variation and its morphology of both sisal fibres are present in Fig. 4 and in Table 3. The Fig. 4 refers to the diameter variation of the fibres in terms of mean and standard deviation, where the average fibre diameter decreases slightly with the surface treatment. Taking in consideration the Gaussian fit curve obtained from the histograms performed for the sisal fibres and presented in Fig. 4a), the unmodified sisal fibre presents a diameter of [117.3-234.5] $\mu \mathrm{m}$ for a confidence interval of $95 \%$. The diameter of the Sisal_NaOH fibre presented in Fig. 4c) was smaller than the unmodified sisal ranging from [85.3-197.7] $\mu \mathrm{m}$ due to the alkali chemical treatment. The small increase on density was observed probably due to increase of the crystallinity after chemical treatment. In terms of morphology, the sisal fibre (Fig. 4b) consists of aligned fibrils with materials cementing the fibres together. After the chemical treatment a small reduction on the cell wall and fibre diameter (see Fig. 4d) was noticed. The alkali treatment leads to fibrillation of the fibre bundle into smaller fibres, reducing the diameter and increases the roughness [10]. After chemical treatment of the fibres, seems to be cleaner when compared with the unmodified sisal fibres.

\subsubsection{Thermal degradation}

The TGA and DTG (first derivative of the TGA) curves of sisal fibres with and without chemical modification under nitrogen atmosphere are presented in Fig. 5a and b respectively. The TGA of the sisal fibre shows a two-step degradation process with a initial transition around $100{ }^{\circ} \mathrm{C}$ is due to moisture evaporation. Cellulose is the main constituent of the cell wall of several lignocellulosic fibres such as wood and sisal. It is established in wood that the cellulose contains numerous hydroxyl groups that are strongly hydrophilic

Table 3

Physical and crystallinity properties of the sisal fibres.

\begin{tabular}{lllll}
\hline Fibre & $\begin{array}{l}\text { Degree of } \\
\text { crystallinity of } \\
\text { cellulose }(\%)\end{array}$ & $\begin{array}{l}\text { Weight loss } \\
\text { after } \\
\text { treatment }(\%)\end{array}$ & $\begin{array}{l}\text { Density }(\mathrm{kg} / \\
\left.\mathrm{m}^{3}\right)\end{array}$ & $\begin{array}{l}\text { Diameter } \\
(\mu \mathrm{m})\end{array}$ \\
& $\mu$ & $\sigma$ & $\sigma$ \\
\hline Sisal & 24.1 & - & $770.0 \pm 62.2$ & $175.9 \pm 29.3$ \\
Sisal_NaOH & 29.6 & 14.2 & $840.9 \pm 96.8$ & $141.5 \pm 28.1$ \\
\hline
\end{tabular}

* Values obtained using the Gauss fit curve with $n=150$ measurements for each condition. 


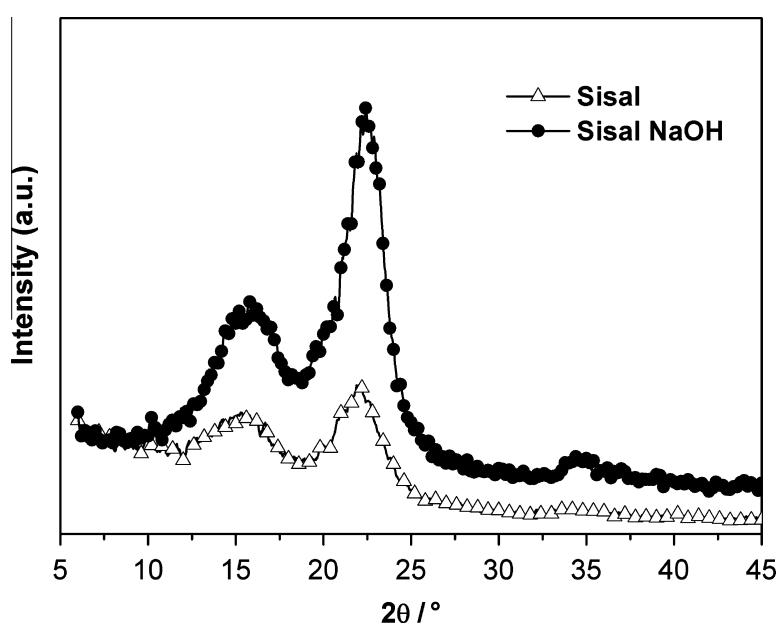

Fig. 3. X-ray diffraction spectra of sisal untreated and alkali treated sisal fibres.

[33]. In the inset graph of Fig. 5a evidences the lower moisture content in the fibres after alkali treatment that induces the hydrophobicity of the fibre. The onset degradation temperature of the alkali treated fibre is very similar to the untreated sisal fibre. With the TGA was possible to confirm that the chemical modification does not induce a negative effect on the thermal resistance of the fibres. Fig. $5 \mathrm{~b}$ presents the derivative curve and was noticed in the fibre with alkali treatment the disappearing of the shoulder around $296-298^{\circ} \mathrm{C}$ that is attributed to the removal the hemicellulose [34], while lignin decomposition extended to the whole range from $200{ }^{\circ} \mathrm{C}$ until $700{ }^{\circ} \mathrm{C}$, due to different activities of the chemical bonds present on its structure $[11,35]$. The more intense degradation peak around $351-364{ }^{\circ} \mathrm{C}$ presented in both fibres could derive from the degradation of cellulosic components present on the sisal fibres. In terms of residual mass at $595{ }^{\circ} \mathrm{C}$ the sisal fibre presents $19.8 \%$ comparing with $24.2 \%$ for the alkali sisal treatment.

\subsubsection{Mechanical properties of sisal fibres}

The tensile properties of the single sisal fibre before and after chemical treatment are presented in Table 4. It is clear the higher tensile properties of the sisal fibre comparing to the thermoplastic polymers such polyethylene and polypropylene. Comparing the properties between the different fibres the mean values of maximum strength of the unmodified sisal is higher compared with the modified fibres. This may be related with the alkali chemical treatment that promoted the reduction of the fibre thickness and some removing of the hemicelluloses and lignin as discussed in the chemical characterization, promoting a more intense yellow colour to the sisal fibre. The obtained high standard deviations values on the tensile test are in part related with the variation in the fibre diameter of the selected natural fibres.
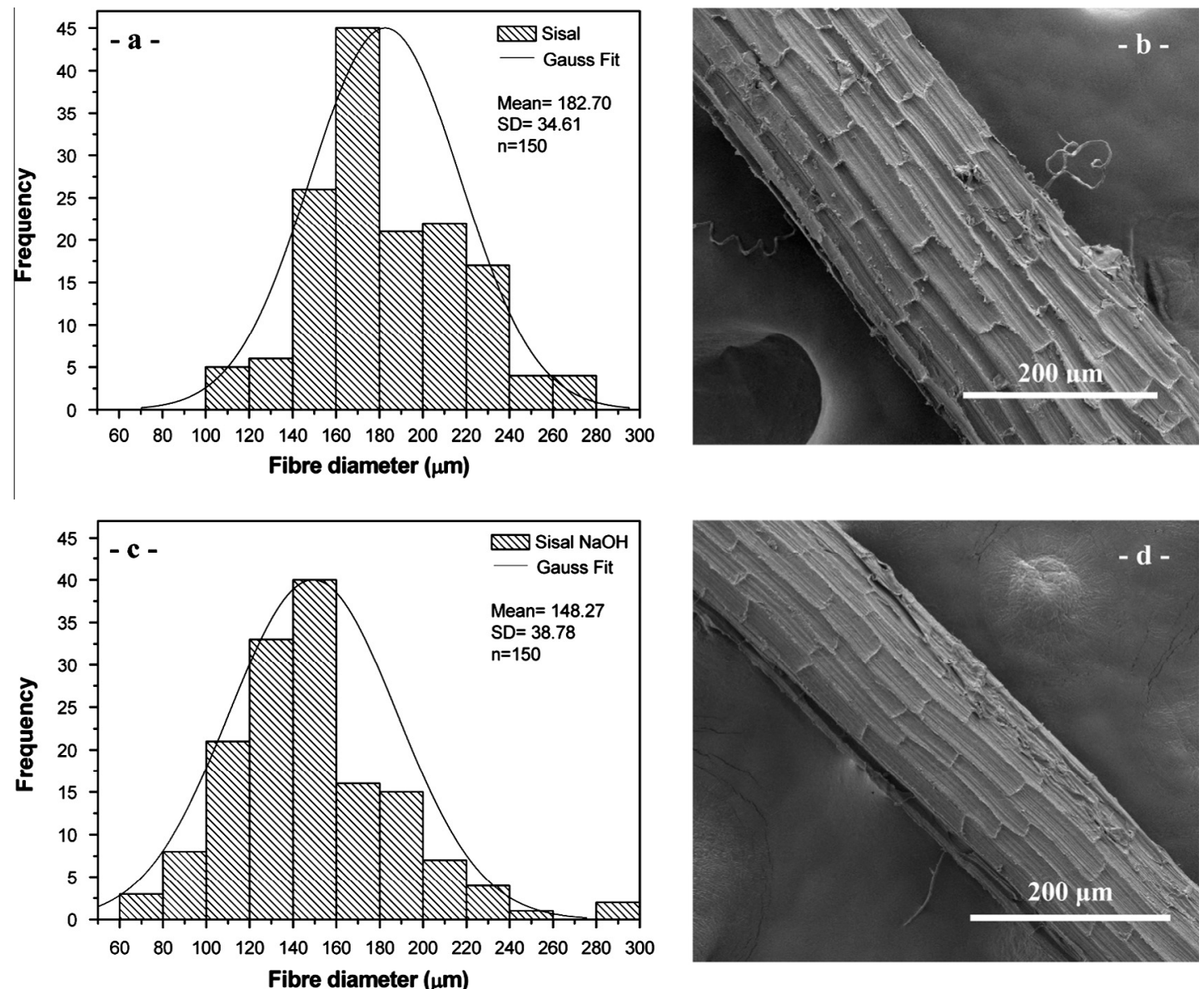

Fibre diameter $(\mu \mathrm{m})$

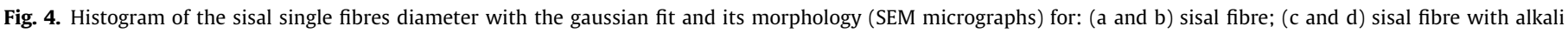
treatment. 

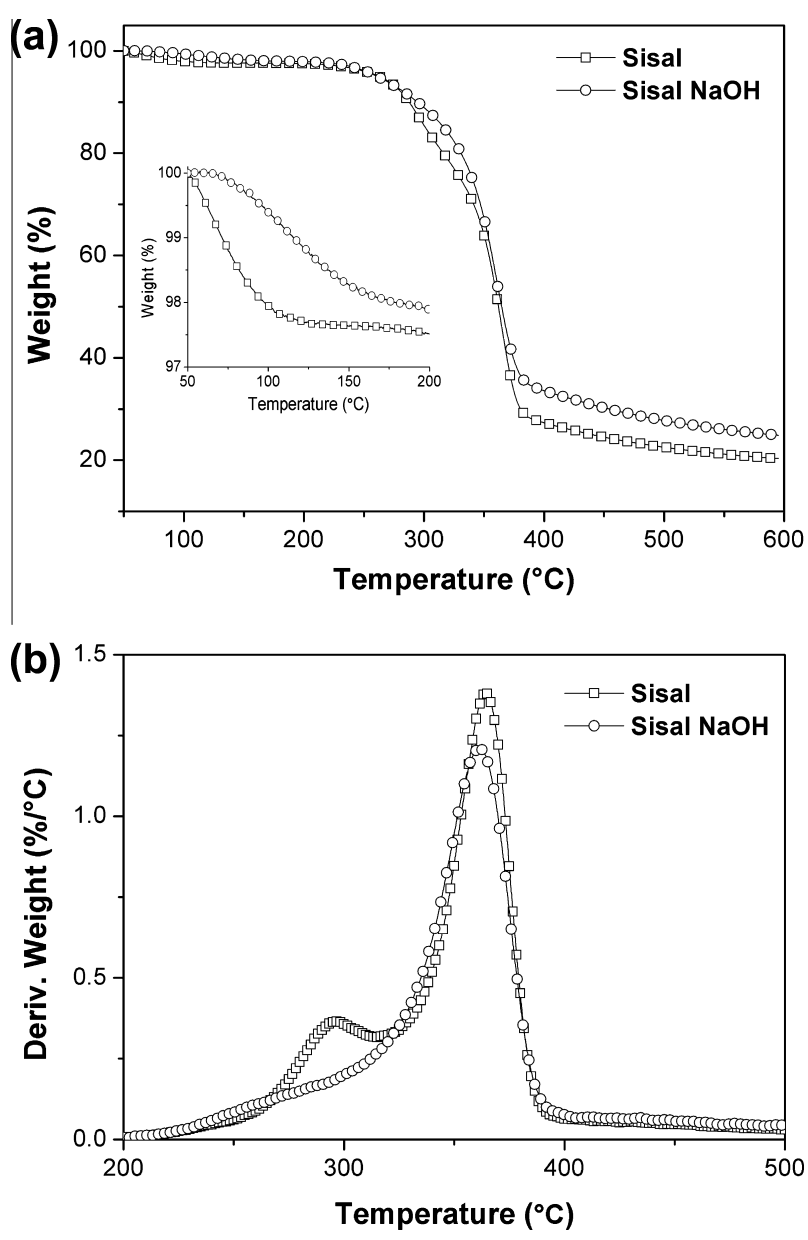

Fig. 5. TGA curves of untreated and treated sisal fibres (a) and respective derivative curves (b).

Table 4

Mechanical properties of the single sisal fibres after uniaxial tensile tests.

\begin{tabular}{llll}
\hline Fibre & $\begin{array}{l}\text { Tensile } \\
\text { modulus (GPa) }\end{array}$ & $\begin{array}{l}\text { Tensile maximum } \\
\text { strength }(\mathrm{MPa})\end{array}$ & $\begin{array}{l}\text { Maximum } \\
\text { deformation (\%) }\end{array}$ \\
\hline Sisal & $12.93 \pm 1.60$ & $372.65 \pm 125.86$ & $3.05 \pm 0.56$ \\
Sisal_NaOH & $12.47 \pm 1.42$ & $298.35 \pm 48.88$ & $3.04 \pm 0.50$ \\
\hline
\end{tabular}

\subsection{Composite morphology}

The properties of short fibre polymer composites are strongly dependent on the fibre volume fraction and on the orientation distribution. The fracture morphology of the cork based composites after tensile tests, obtained by scanning electron microscopy is presented in Fig. 6. In the micrographs of Fig. $6 a$ and $b$ it is possible to observe the good adhesion between the cork and the polymeric matrix promoted by the use of the coupling agent. When the sisal fibres are added to the cork-polymer without the use of coupling agent (Fig. $6 c$ and d), the fracture reveal voids from the pull-out of the sisal fibre indicating lower adhesion between the sisal fibres to the matrix. Additionally and at high magnification it was also observed the polymeric phase presents some stretching as compared with the previous composite CPC 2. Similar observation after mechanical tests was registered in a previous work using cork based composites obtained by pultrusion (pellets) follow by compression moulding [16]. Regarding the fibres with the alkali treatment we clearly observe at high magnification (Fig. 6f) particles of cork that are in contact along to the sisal fibre and there is a good linkage between the fibres and the matrix. The improvement of the adhesion was obtained by the combine effect of the low amount of coupling agent $2 \mathrm{wt} . \%$ and the chemical modification of the sisal fibres.

\subsection{Mechanical properties of composites}

\subsubsection{Tensile tests}

Tensile tests were performed in order to evaluate the mechanical performance of the novel hybrid cork composites. Fig. 7 summarizes the obtained properties, in terms of tensile modulus and maximum strength for the composites with polyethylene matrix. The statistical significance between samples with and without sisal fibre reinforcement was compared, being CPC 2 the cork-polymer composite reinforced with 2 wt.\% of coupling agent. Considering the data of Fig. 7, it is clear the effect of the coupling agent on the increase in terms of tensile strength $(16.8 \%)$ for the composites CPC 1 and CPC 2 containing polymer and cork as main constituents. This result it is in agreement with a previous study [17] when it was used $50 \mathrm{wt}$.\% of cork powder from different industrial processes by pultrusion and compression moulding on the development of composites. The addition of $10 \mathrm{wt} . \%$ of unmodified sisal fibre (CPC 3), leads to a significant reinforcement in terms of modulus of $23 \%$. Additionally, the sisal fibres and the cork act as filler since it reduces the strength due to the increase of the natural component on the hybrid composite. CPC 4 presents the same composition as CPC 3 where the difference was the two extrusion step process to produce the composite pellets. The cork-polymer were first compounded into composite pellets and then short sisal fibres were added in the cork-polymer composite pellets, to produce the hybrid reinforced composite. We observed that no improvements were noticed when we used a two-step extrusion process to produce the same hybrid composites. CPC 5 and CPC 6 are similar in terms of composition (see Table 2 ), where the important difference was the fibre treatment. Regarding the CPC 5 we can observe that the addition of $10 \mathrm{wt} . \%$ of sisal fibres in the presence of coupling agent 2 wt.\% improved significantly both stiffness in $22 \%$ and the tensile strength in $28 \%$ of the hybrid composite. The improvement on the tensile properties was even higher by using the alkali treated sisal fibres, being $29 \%$ and $49 \%$ respectively due to the chemical surface modification and increase of surface roughness. Comparing with the polyethylene matrix, the developed hybrid cork based composites presents similar modulus values but a reduced strength performance. In the literature it is pointed that the use of coupling agents based on maleic anhydride (MA) increases the tensile strength of the composites due to the esterification reaction between sisal fibre hydroxyl groups and anhydride part which causes a reduction in interfacial tension and an increase in interfacial adhesion between thermoplastic and the fibre [36]. Similar hydroxyl groups are present in the chemical composition of cork and sisal fibres. The combined effect of the sisal fibre treatment with the presence of coupling agent based on MA for effective stress transfer across the interface enhances the adhesion between the interphases and consequently reinforces the tensile properties of the hybrid cork-polymer composites.

\subsubsection{Flexural tests}

Fig. 8 displays representative stress-strain curves of the polyethylene matrix and the prepared cork composites with and without the reinforcement of sisal fibres after a three-point bending test. Fig. 9 presents the corresponding flexural modulus and the maximum strength mean values with the respective standard deviation for comparison. Similar to the tensile behaviour results of the composites, the addition of $10 \mathrm{wt} . \%$ of sisal fibre without coupling agent (CPC 3) improves the stiffness; however it reduces signifi- 

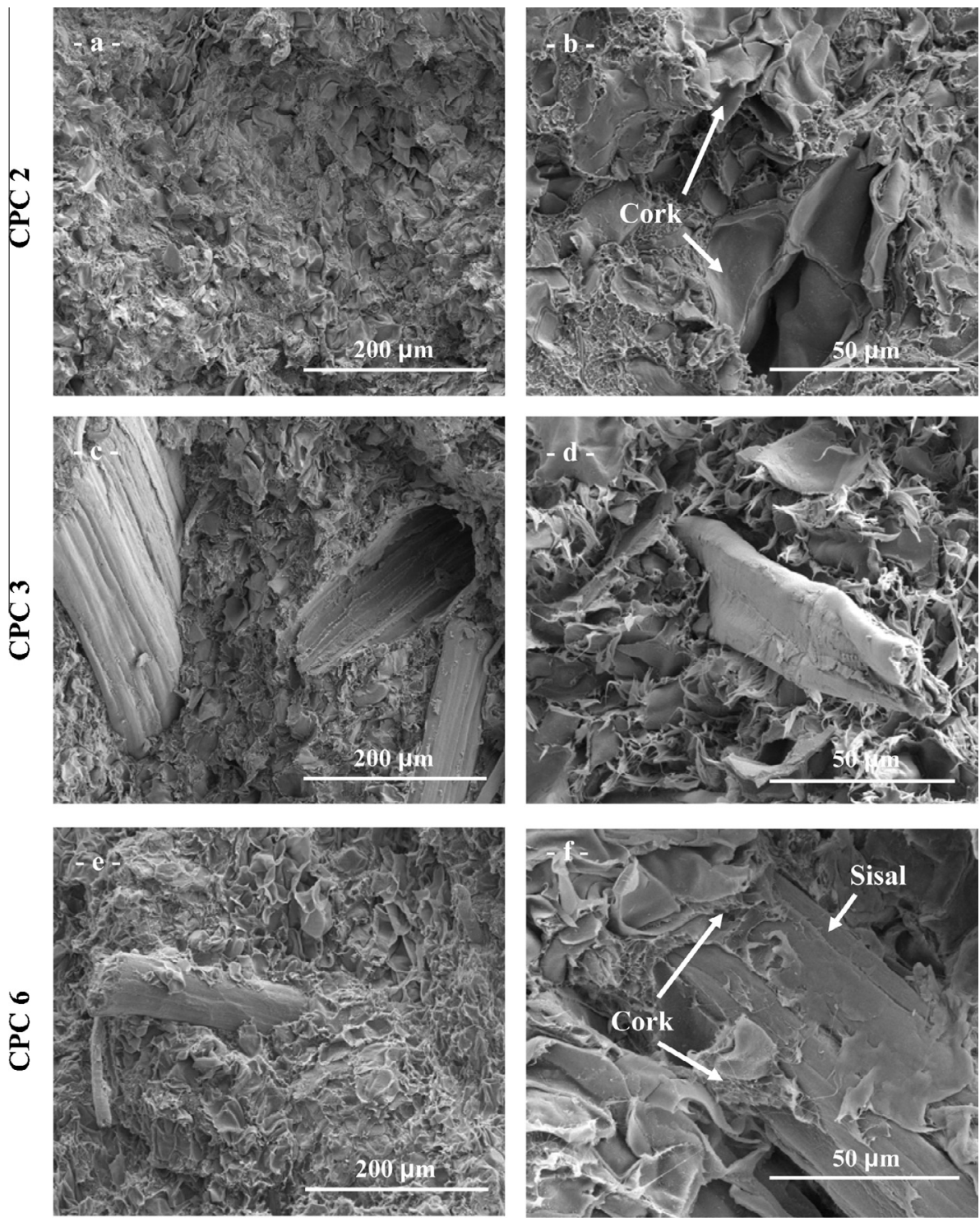

Fig. 6. Fracture morphology at two different magnifications of the hybrid composite materials after tensile tests.

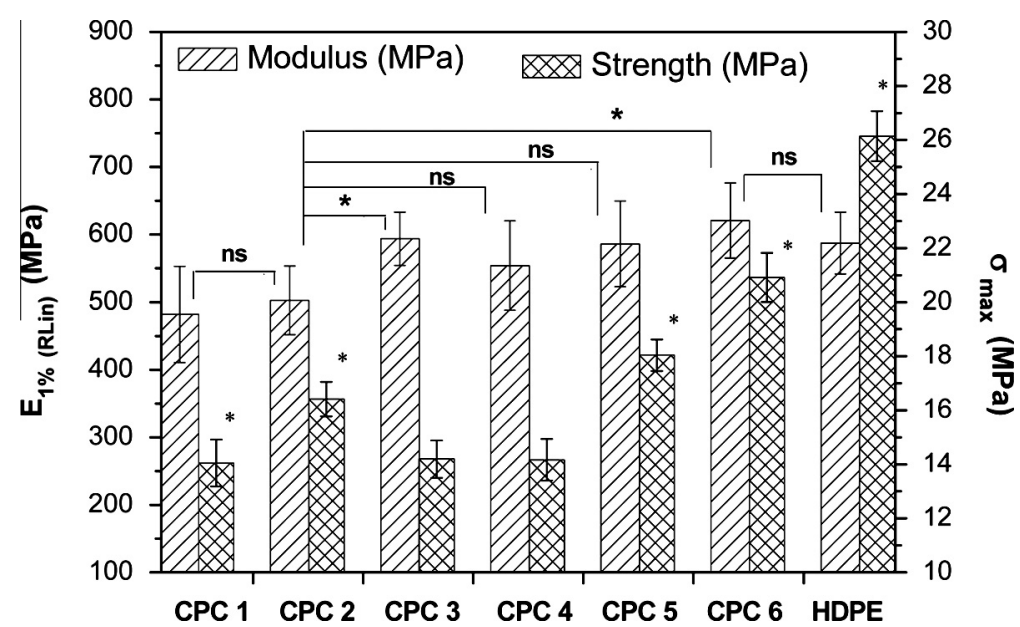

Fig. 7. Mechanical properties of the reinforced cork-polymer composites with sisal fibres, when submitted to uniaxial tensile load. (*) Significant at 0.05 ; ns: non-significant at 0.05 . 


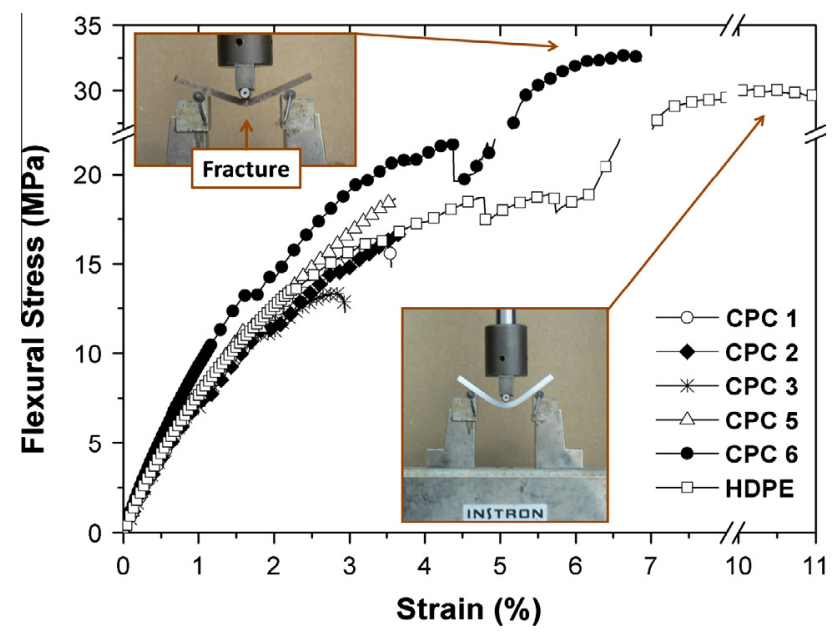

Fig. 8. Representative flexural stress-strain curves of the developed cork-polymer composites (40-60 wt.\%) reinforced, or not, with sisal fibres.

cantly the flexural strength (see Fig. 9) and reduces the strain at break as showing in Fig 8. The addition of coupling agent promotes mainly the flexural strength and the elongation at break (CPC 5). After chemical modification the resulting sisal fibres present a rough surface topography, with removal of surface impurities and removal of hydrophilic hydroxyl groups [30] improving the affinity with the thermoplastic matrix. The combined effect of the chemical modification of sisal and the use of $2 \mathrm{wt} . \%$ of coupling agent (CPC 6) result in hybrid composites with enhanced flexural performance. Comparing with the unreinforced composite CPC 1 , it has higher stiffness 33\%, higher flexural strength $98 \%$ and higher elongation at break due to the improvement on the interfacial adhesion between the matrix and the natural component.

Additionally, it was possible to reinforce the high density polyethylene matrix in terms of modulus (16\%) and strength (11\%) at flexural load mainly after the sisal fibres alkali treated. In the literature it was found that the sisal fibre after alkali modification improves the dispersion of the fibres but not their adhesion to the polymer matrix, due to a higher availability of $\mathrm{OH}$ groups in the particles surface [37]. Alkali treatment may leads to fibre fibrillation i.e. breaking down of fibre bundles into smaller fibres; which increases the surface area available for contact with the matrix [32]. The treatment is in accordance with the morphology results obtained, leading to a considerable enhancement on the mechani-

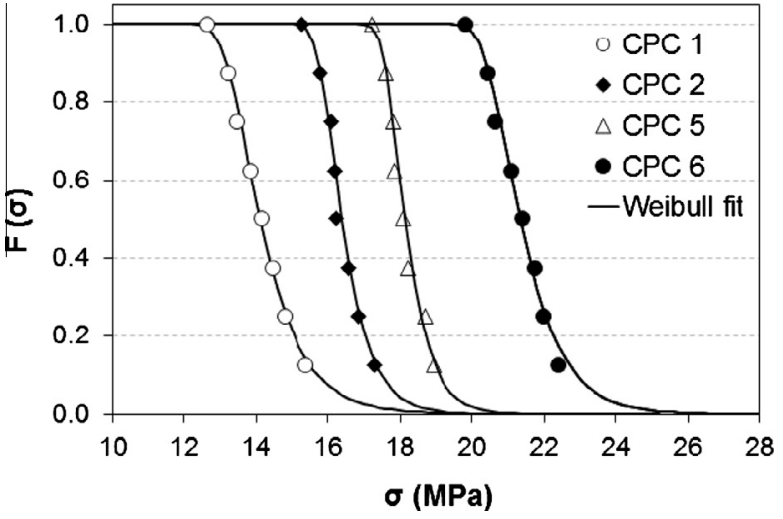

Fig. 10. Tensile strength of the cork-polymer composites reinforced with sisal fibre. Lines show Weibull distribution with parameters values shown in Table 4.

cal properties. Higher improvements might be achieved by using higher amount of the natural fibre based in the presence of coupling agent. However, the high increase of the viscosity will make difficult the melt based processes of formulations riches in natural materials based on fibres and particles.

\subsection{Weibull statistical analysis}

Tensile strength life distribution diagrams have been obtained by using the cumulative Weibull distribution function (Eq. (2)) for cork-polymer composite reinforced with sisal fibres. Fig. 10 presents the reliability probability of survival $(F)$ and can be found easily corresponding to any stress value from the diagram. The Weibull fit method was used to modelling the failure data of the hybrid composites when submitted to tensile load and compare the increase on the strength promoted by the sisal chemical modification. A very good agreement between the estimated strengths and experimental values is evident in Table 5, confirming the efficiency of the Weibull distribution in prediction the tensile strength failure properties of the developed hybrid composites. The tested composites present strength higher than $12.65 \mathrm{MPa}$ see Fig. 10 . Comparing the estimated strength or probability of failure at $95 \%$ of confidence present in Table 5 for the cork-polymer composites (40-60) wt.\%, the use of coupling agent improved in 20\% the strength of the composite. The addition of the untreated sisal fibres with coupling agent (CPC 5) presents a higher improvement of 34\% comparing with CPC 1 and an increase of $12 \%$ comparing with the CPC 2. The best results were obtained with sisal treated fibres,

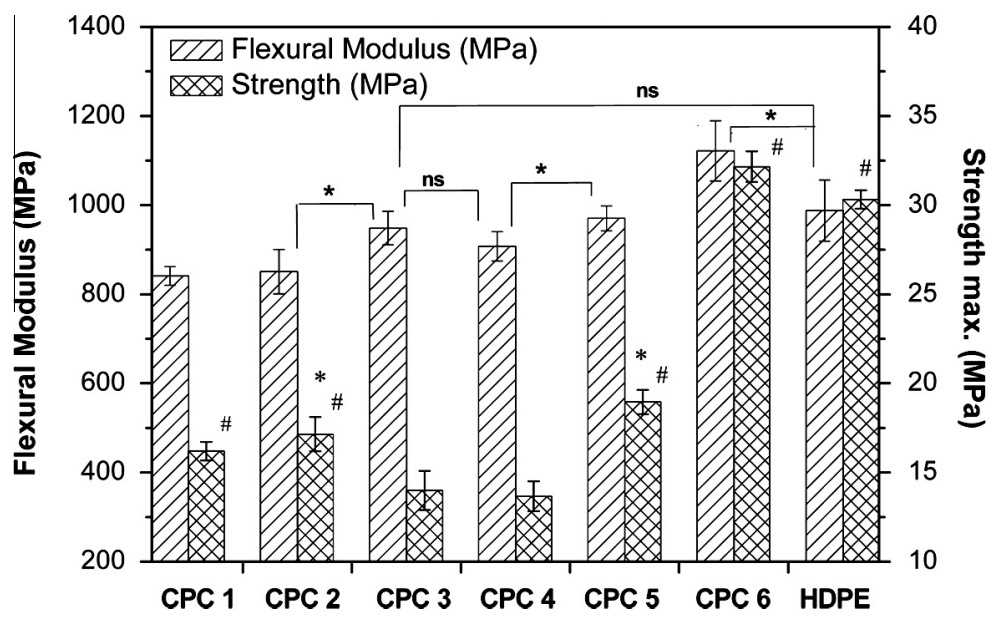

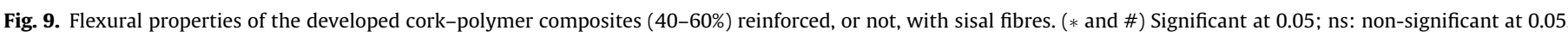


Table 5

Weibull distribution parameters, estimated tensile strength for the composites at 95\% and 99\% of confidence, obtained experimental results and KS goodness-of-fit-test.

\begin{tabular}{|c|c|c|c|c|c|c|c|}
\hline \multirow[t]{2}{*}{ Composite } & \multicolumn{2}{|c|}{ Distribution parameters } & \multicolumn{2}{|c|}{ Estimate strength (MPa) } & \multirow{2}{*}{$\begin{array}{l}\text { Experimental value (MPa) } \\
\text { Max. strength }\end{array}$} & \multicolumn{2}{|c|}{$\mathrm{K}-\mathrm{S}$ test } \\
\hline & $\alpha$ & $\beta$ & $p<0.05$ & $p<0.001$ & & $D_{n}$ & $D_{n c}$ \\
\hline CPC 1 & 13.81 & 17.49 & 13.0 & 12.6 & $14.04 \pm 0.87$ & 0.17 & 0.358 \\
\hline CPC 2 & 16.19 & 29.60 & 15.6 & 15.4 & $16.41 \pm 0.64$ & 0.23 & 0.358 \\
\hline CPC 5 & 17.96 & 36.97 & 17.4 & 17.2 & $18.03 \pm 0.58$ & 0.23 & 0.358 \\
\hline CРC 6 & 21.05 & 26.76 & 20.2 & 19.8 & $20.92 \pm 0.91$ & 0.19 & 0.358 \\
\hline
\end{tabular}

\pm Standard deviation values.

mostly using the sisal modified with $\mathrm{NaOH}$ that presents an increase of $55 \%$ and $30 \%$ comparing with the CPC 1 and CPC 2, respectively. Several methods, such as Chi-square, the Anderson-Darling test, allows to determine the goodness of fit of a probability distribution to a set of data [24,38]. In this study, the goodness-of-fit test was carried out by using the Kolmogorov-Smirnov (K-S) test that is used for statistical analysis of composites. The procedure was partially adapted from [39]:

(1) Since the K-S is a distance test, it was determined the maximum deviation $\left(D_{n}\right)$ from $D^{+}=F_{n}-\mathrm{F}_{0}$ and $D^{-}=F_{0}-F_{n-1}$. Being $F_{n}$ the cumulative observed values and $F_{0}$ the Weibull cumulative distribution function present in the Eq. (2).

(2) $\mathrm{K}-\mathrm{S}$ tables of critical values (CV) are valid when the distribution parameters are known. Since the distribution parameters were estimated from the experimental data the CV will be $4 \times \alpha$ value [24], i.e. for a significance level of $\alpha=0.05$ that means $\alpha^{\prime}=0.20$. For $n=8$ and a significance level of $\alpha=0.05$, the $D_{n c}=0.358$.

(3) If $D_{n}<D_{n c}$, the null hypothesis that the observed data follow the Weibull distribution is accepted.

The Weibull parameters and K-S goodness-of-fit test are listed in Table 5 . The K-S statistic $D_{n}$ values presented in Table 5 and obtained after the test are between 0.17 and 0.23 , indicating that the tensile strength of the developed hybrid composites is strongly explained by the Weibull cumulative distribution because it departs significantly from the value of significance level $\alpha=0.05$ and a sample size of $n=8$ for which the K-S of fit test was performed.

\section{Conclusions}

Cork-polymer composites (CPC) reinforced with sisal discontinuous fibres has shown to be a viable strategy to obtaining structural materials with improved mechanical performances in terms of tensile and flexural properties. The improvement on the mechanical properties was effective when a $2 \mathrm{wt} . \%$ of coupling agent based on maleic anhydride (MA) was used, since the mechanical properties increased in terms of stiffness, strength and elongation at break. The improvement of the interfacial adhesion between the matrix, the cork and sisal fibres was also confirmed by the fracture morphology. In terms of processing to obtain the hybrid CPC pellets, there is no advantage in the use of two melt extrusion steps and add the sisal fibres only in the second step. This study demonstrates that the mechanical properties of CPC can be improved by: (1) the addition of a $2 \mathrm{wt} . \%$ of the coupling agent based on MA; (2) the sisal fibres addition (10 wt.\%) without the use of a coupling agent, resulting in a hybrid CPC with similar modulus properties and with lower thermoplastic content and (3) by the combined effect of the addition of alkali treated sisal fibres with the use of the coupling agent resulting in composites with considerably higher mechanical properties. Under flexural load and using alkali treated sisal fibres with coupling agent in the new composites an increase of 33\% in modulus and an increase of $98 \%$ in strength were obtained when compared with unreinforced cork composites. Comparing the improved mechanical properties of the hybrid CPC with the polyethylene matrix, it was possible to reinforce the matrix in terms of stiffness and strength at flexural load manly after the sisal fibres alkali treatment. In terms of tensile strength, they present similar stiffness and lower strength when compared to the polyethylene matrix. The Weibull diagram was used to reliably identify the composites safety limits. The tensile strength of the hybrid reinforced CPC was found to be in agreement with the Weibull cumulative distribution, which can be used to accurately predict the mechanical performances in terms of strength of the developed hybrid cork composite materials.

\section{Acknowledgments}

We gratefully acknowledge to Amorim Revestimentos S.A. for the supply of cork and to Pallmann GmbH for the polymer in the grinding form. To QREN FCOMP-01-0202-FEDER-003107 financing support on the project "NovelComp". EMF acknowledge to Portuguese Foundation for Science and Technology (FCT) Grant (SFRH/ $\mathrm{BD} / 71561 / 2010)$.

\section{References}

[1] Kalia S, Kaith BS, Kaur I. Pretreatments of natural fibers and their application as reinforcing material in polymer composites - a review. Polym Eng Sci 2009;49(7):1253-72.

[2] Saheb DN, Jog JP. Natural fiber polymer composites: a review. Adv Polym Technol 1999;18(4):351-63.

[3] Faruk O, Bledzki AK, Fink H-P, Sain M. Biocomposites reinforced with natural fibers: 2000-2010. Prog Polym Sci 2012;37(11):1552-96.

[4] Kabir MM, Wang H, Lau KT, Cardona F. Chemical treatments on plant-based natural fibre reinforced polymer composites: an overview. Composites Part B 2012;43(7):2883-92.

[5] Bledzki AK, Gassan J, Theis S. Wood-filled thermoplastic composites. Mech Compos Mater 1998;34(6):563-8.

[6] George J, Sreekala MS, Thomas S. A review on interface modification and characterization of natural fiber reinforced plastic composites. Polym Eng Sci 2001;41(9):1471-85.

[7] Li X, Tabil LG, Panigrahi S. Chemical treatments of natural fiber for use in natural fiber-reinforced composites: a review. J Polym Environ 2007;15(1):25-33.

[8] John MJ, Anandjiwala RD. Recent developments in chemical modification and characterization of natural fiber-reinforced composites. Polym Compos 2008;29(2):187-207.

[9] Pandey JK, Ahn SH, Lee CS, Mohanty AK, Misra M. Recent advances in the application of natural fiber based composites. Macromol Mater Eng 2010;295(11):975-89.

[10] Bogoeva-Gaceva G, Avella M, Malinconico M, Buzarovska A, Grozdanov A, Gentile G, et al. Natural fiber eco-composites. Polym Compos 2007;28(1):98-107.

[11] Barreto ACH, Rosa DS, Fechine PBA, Mazzetto SE. Properties of sisal fibers treated by alkali solution and their application into cardanol-based biocomposites. Compos Part A - Appl Sci 2011;42(5):492-500.

[12] Gassan J, Bledzki AK. Alkali treatment of jute fibers: relationship between structure and mechanical properties. J Appl Polym Sci 1999;71(4):623-9.

[13] Silva SP, Sabino MA, Fernandes EM, Correlo VM, Boesel LF, Reis RL. Cork: properties, capabilities and applications. Int Mater Rev 2005;50(6):345-65.

[14] Gil L. Cork composites: a review. Mater Des 2009;2:776-89.

[15] Abdallah FB, Cheikh RB, Baklouti M, Denchev Z, Cunha AM. Effect of surface treatment in cork reinforced composites. J Polym Res 2009;17(4):519-28. 
[16] Fernandes EM, Correlo VM, Chagas JAM, Mano JF, Reis RL. Properties of new cork-polymer composites: advantages and drawbacks as compared with commercially available fibreboard materials. Compos Struct 2011;93(12):3120-9.

[17] Fernandes EM, Correlo VM, Chagas JAM, Mano JF, Reis RL Cork based composites using polyolefin's as matrix: Morphology and mechanical performance. Compos Sci Technol 2010;70(16):2310-8.

[18] Brook G. Silicone-fiber-cork ablative insulation material. EP1482163-A3 United Technologies Corporation; 2004.

[19] Fernandes EM, Silva VM, Chagas JAM, Reis RL. Fibre-reinforced cork-based composites. WO2011014085-A2, Amorim Revestimentos, S.A.; 2011.

[20] Fernandes EM, Correlo VM, Mano JF, Reis RL. Novel cork-polymer composites reinforced with short natural coconut fibres: effect of fibre loading and coupling agent addition. Compos Sci Technol 2013;78:56-62.

[21] Thwe MM, Liao K. Durability of bamboo-glass fiber reinforced polymer matrix hybrid composites. Compos Sci Technol 2003;63(3-4):375-87.

[22] Thomas S, Pothan L. Natural fibre reinforced polymer composites: from macro to nanoscale. Old City Publishing Inc.; 2009.

[23] Li Y, Mai YW. Interfacial characteristics of sisal fiber and polymeric matrices. J Adhesion 2006;82(5):527-54.

[24] Lawless JF. Statistical models and methods for lifetime data. New York: John Wiley and Sons; 1982.

[25] Gañan P, Garbizu S, Llano-Ponte R, Mondragon I. Surface modification of sisal fibers: effects on the mechanical and thermal properties of their epoxy composites. Polym Compos 2005;26(2):121-7.

[26] Bledzki AK, Reihmane S, Gassan J. Properties and modification methods for vegetable fibers for natural fiber composites. J Appl Polym Sci 1996;59(8):1329-36.

[27] Gil L. Cortiça: produção, tecnologia e aplicação. INETI, Lisbon; 1998.
28] Huda MS, Drzal LT, Mohanty AK, Misra M. Effect of fiber surface-treatments on the properties of laminated biocomposites from poly(lactic acid) (PLA) and kenaf fibers. Compos Sci Technol 2008;68(2):424-32.

[29] Caprino G, Giorleo G, Nele L, Squillace A. Pin-bearing strength of glass mat reinforced plastics. Compos Part A - Appl Sci 2002;33(6):779-85.

[30] Mwaikambo LY, Ansell MP. Chemical modification of hemp, sisal, jute, and kapok fibers by alkalization. J Appl Polym Sci 2002;84(12):2222-34.

[31] Rong MZ, Zhang MQ Liu Y, Yang GC, Zeng HM. The effect of fiber treatment on the mechanical properties of unidirectional sisal-reinforced epoxy composites. Compos Sci Technol 2001;61(10):1437-47.

[32] Li Y, Mai YW, Ye L. Sisal fibre and its composites: a review of recen developments. Compos Sci Technol 2000;60(11):2037-55.

[33] Ichazo MN, Albano C, Gonzalez J. Behavior of polyolefin blends with acetylated sisal fibers. Polym Int 2000;49(11):1409-16.

[34] Martins MA, Joekes I. Tire rubber-sisal composites: effect of mercerization and acetylation on reinforcement. J Appl Polym Sci 2003;89(9):2507-15.

[35] Yang H, Yan R, Chen H, Lee DH, Zheng C. Characteristics of hemicellulose, cellulose and lignin pyrolysis. Fuel 2007;86(12-13):1781-8.

[36] Joseph PV, Joseph K, Thomas S. Short sisal fiber reinforced polypropylene composites: the role of interface modification on ultimate properties. Compos Interface 2002;9(2):171-205.

[37] Ichazo MN, Albano C, González J, Perera R, Candal MV. Polypropylene/wood flour composites: treatments and properties. Compos Struct 2001:54(23):207-14.

[38] Alqam M, Bennett RM, Zureick A-H. Three-parameter vs. two-parameter Weibull distribution for pultruded composite material properties. Compos Struct 2002;58(4):497-503.

[39] Zhang Y, Wang X, Pan N, Postle R. Weibull analysis of the tensile behavior of fibers with geometrical irregularities. J Mater Sci 2002;37(7):1401-6. 